\title{
Morphology and Shear Strength of Lead-Free Solder Joints with Sn3.0Ag0.5Cu Solder Paste Reinforced with Ceramic Nanoparticles
}

\author{
A. YAKYMOVYCH,,$^{1,2,5}$ YU. PLEVACHUK, ${ }^{2}$ P. ŠVEC SR. ${ }^{3}$ P. ŠVEC ${ }^{3}$ \\ D. JANIČKOVIČ ${ }^{3}$ P. ŠEBO,${ }^{4}$ N. BERONSKÁ, ${ }^{4}$ A. ROSHANGHIAS, ${ }^{1}$ \\ and H. IPSER ${ }^{1}$
}

1.-Department of Inorganic Chemistry - Functional Materials, University of Vienna, Währinger Str. 42, 1090 Vienna, Austria. 2.-Department of Metal Physics, Ivan Franko National University, Kyrylo and Mephodiy str. 8, Lviv 79005, Ukraine. 3.-Department of Metal Physics, Institute of Physics, Slovak Academy of Sciences, Dubravska cesta 9, 84511 Bratislava, Slovakia. 4.-Institute of Materials and Machine Mechanics, Slovak Academy of Sciences, Račianska 75, 83102 Bratislava, Slovakia. 5.—e-mail: andriy.yakymovych@univie.ac.at

To date, additions of different oxide nanoparticles is one of the most widespread procedures to improve the mechanical properties of metals and metal alloys. This research deals with the effect of minor ceramic nanoparticle additions $\left(\mathrm{SiO}_{2}, \mathrm{TiO}_{2}\right.$ and $\left.\mathrm{ZrO}_{2}\right)$ on the microstructure and mechanical prop-

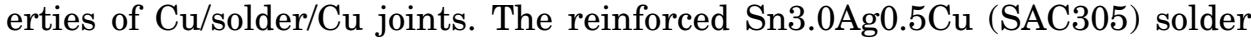
alloy with 0.5 wt.\% and 1.0 wt.\% of ceramic nanoparticles was prepared through mechanically stirring. The microstructure of as-solidified $\mathrm{Cu} / \mathrm{solder} /$ $\mathrm{Cu}$ joints was studied using scanning electron microscopy. The additions of ceramic nanoparticles suppressed the growth of the intermetallic compound layer $\mathrm{Cu}_{6} \mathrm{Sn}_{5}$ at the interface solder/Cu and improved the microstructure of the joints. Furthermore, measurements of mechanical properties showed improved shear strength of $\mathrm{Cu} /$ composite solder/Cu joints compared to joints with unreinforced solder. This fact related to all investigated ceramic nanoinclusions and should be attributed to the adsorption of nanoparticles on the grain surface during solidification. However, this effect is less pronounced on increasing the nanoinclusion content from $0.5 \mathrm{wt} . \%$ to $1.0 \mathrm{wt} . \%$ due to agglomeration of nanoparticles. Moreover, a comparison analysis showed that the most beneficial influence was obtained by minor additions of $\mathrm{SiO}_{2}$ nanoparticles into the SAC305 solder alloy.

Key words: $\mathrm{Sn} 3.0 \mathrm{Ag} 0.5 \mathrm{Cu}$, ceramic nanoparticles, microstructure, shear strength

\section{INTRODUCTION}

The trend of the electronics industry toward further miniaturization entails great challenges for researchers to develop novel lead-free solders in order to improve the reliability of solder joints. Recent investigations have shown an improvement of the microstructure and mechanical properties by

(Received April 20, 2016; accepted July 26, 2016 ;

published online August 5, 2016) minor additions of nanosized particles into lead-free solders. ${ }^{1-4}$ For instance, nano $\gamma-\mathrm{Fe}_{2} \mathrm{O}_{3}$ and nano $\mathrm{ZnO}$ additions reinforced the microstructure of nanocomposite $\mathrm{SnAgCu}$ solders, ${ }^{1,4}$ the wettability was increased with additions of nano $\gamma-\mathrm{Fe}_{2} \mathrm{O}_{3}$ and $\mathrm{Ni}$-coated graphene nanosheets, ${ }^{1,2}$ and the strength was also increased with additions of nano $\gamma-\mathrm{Fe}_{2} \mathrm{O}_{3}$ and nano $\mathrm{ZnO} .^{1,4}$ Furthermore, additions of nano $\mathrm{Al}$ enhanced the creep resistance of $\mathrm{SnAgCu}$ solder. ${ }^{3}$ Additionally, several review papers gave an overview over a large number of experimental results of 
such investigations; they discussed and tried to clarify the interaction mechanism between solder matrix and nanoinclusions leading to changes both in the microstructure and in different physicochemical properties of nanocomposite solders and the corresponding joints. ${ }^{5-8}$ For instance, it has been shown that small additions of metal $(\mathrm{Ag}, \mathrm{Co}$, $\mathrm{Ni}, \mathrm{Zn}$, etc.) and ceramic nanoparticles $\left(\mathrm{Al}_{2} \mathrm{O}_{3}, \mathrm{SiO}_{2}\right.$, $\mathrm{SnO}_{2}, \mathrm{TiO}_{2}, \mathrm{ZrO}_{2}$, etc.) improve the microhardness and the tensile strength of the solder as well as the shear strength of the solder joint. These improvements are connected with the suppression of the growth rate of intermetallic compounds (IMCs) and a decrease of the grain size of IMCs in the bulk as well as the reduction of the average size of the IMC layer at the interface solder/substrate. ${ }^{9,10}$ However, some literature studies showed that an excessive amount of ceramic nanoadditions in the solder matrix, i.e. more than $1 \mathrm{wt} . \%$, leads to a decrease of these effects for $\mathrm{Sn}-\mathrm{Ag}-\mathrm{Cu}$ (SAC) solder joints. For instance, the shear strength of SAC solder joints was reduced for contents of more than $1.0 \mathrm{wt} . \%$ of nano $\mathrm{SiO}_{2}{ }^{11}$ and nano $\mathrm{TiO}_{2} .{ }^{12}$ It was supposed that an agglomeration occurs to decrease the high surface energy of nanoparticles. As a result, this sideeffect is responsible for a reduction of the improving effects, because nanoparticle agglomerates are generated both in the solder matrix and at the interface solder/substrate in the solder joints. In contrast, Gain et al. ${ }^{13}$ reported a continuous increase of the shear strength for Sn3.0Ag0.5Cu (wt.\%) (SAC305) solder joints reinforced with nano $\mathrm{ZrO}_{2}$ up to $3.0 \mathrm{wt} . \%$. On the other hand, Tsao et al. ${ }^{9}$ indicated an insignificant increase of this feature within the addition interval between $0.25 \mathrm{wt} . \%$ and $1.00 \mathrm{wt} . \%$ of nano $\mathrm{Al}_{2} \mathrm{O}_{3}$.

In Refs. 14-16 it was suggested that, using nanocomposite solder paste, nanoparticles move during the reflow process with the flux. Tay et al. ${ }^{15}$ indicated that after reflow the actual concentration of nanoparticles in the nanocomposite Sn3.8Ag0.7Cu (SAC387) solder reinforced with nano $\mathrm{Ni}$ was smaller compared to that in the flux residual. Moreover, the mobility rate of nanoparticles should be different due to the difference in density between a solder and nanoinclusions, as has been reported for effects of $\mathrm{Fe}_{2} \mathrm{NiO}_{4}$ nanosized additions into a SAC305 solder paste. ${ }^{14}$

Due to different thermal conditions (reflow time and reflow peak temperature) and different substrates used to make joints (pure $\mathrm{Cu}$, copper organic solderability preservative (Cu-OSP), or electroless nickel immersion gold (ENIG)), it is excessively difficult or even impossible to perform a quantitative analysis of the effects of different ceramic nanoinclusions, based on literature data. In addition, authors used ceramic nanoparticles with different average size between $15 \mathrm{~nm}^{10}$ and $100 \mathrm{~nm},{ }^{17}$ which should have consequences due to possible agglomeration processes of the nanoparticles during reflow. To our knowledge, there is no experimental investigation related to the influence of adding different ceramic nanoparticles on the SAC solder joints. The main goal of this paper is to analyze and compare the effects of minor $\mathrm{SiO}_{2}, \mathrm{TiO}_{2}$ and $\mathrm{ZrO}_{2}$ nanoadditions on the microstructure and shear strength of the SAC305 solder joints. The chosen ceramic nanoparticles had the same average size $(10-15 \mathrm{~nm})$ while the difference in densities between the lightest $\left(\mathrm{SiO}_{2}\right)$ and the heaviest $\left(\mathrm{ZrO}_{2}\right)$ is about a factor of two (Table I). Furthermore, all ceramic nanopowders used in our measurements are lighter than the SAC305 solder $\left(\sim 7.50 \times 10^{3} \mathrm{~kg} \mathrm{~m}^{-318}\right)$. Therefore, this study also discusses the relationship between observed effects of ceramic nanoadditions and the mobility rates of nanoparticles in the SAC305 solder paste.

\section{EXPERIMENTAL PROCEDURES}

Nanocomposite solder pastes were prepared by manually mixing the SAC305 solder paste (NP-505, Kester, U.S.A) with $\mathrm{SiO}_{2}, \mathrm{TiO}_{2}$, and $\mathrm{ZrO}_{2}$ nanopowders (average particle size 10-15 nm, TECNAN, Spain) at a nominal percentage $0 \mathrm{wt} . \%, 0.5 \mathrm{wt} . \%$ and $1 \mathrm{wt} . \%$ (related to the mass of the solder paste) for at least $30 \mathrm{~min}$ to achieve a homogeneous distribution of nanoparticles in the solder paste. ${ }^{19,20}$

The $3 \mathrm{~mm}$ thick $\mathrm{Cu}$ substrates with diameters of $10 \mathrm{~mm}$ and $15 \mathrm{~mm}$ were ground and polished with $1 \mu \mathrm{m}$ and $0.3 \mu \mathrm{m} \mathrm{Al} \mathrm{Al}_{2} \mathrm{O}_{3}$ powders, cleaned with ethanol and immerged into a 10 vol.\% sulfuric acid solution (10 vol.\% $\mathrm{H}_{2} \mathrm{SO}_{4}+90$ vol. $\left.\% \mathrm{C}_{2} \mathrm{H}_{5} \mathrm{OH}\right)$ for $2 \mathrm{~min}$. to remove the oxide layer on the surface. The $\mathrm{Cu} /$ solder/Cu holders were placed into an electric resistance furnace and the joints were prepared in air atmosphere at $523 \mathrm{~K}$ during $300 \mathrm{~s}$ (Fig. 1). After the reflow, the solder joints were cleaned to remove flux residue.

To characterize the microstructure, one part of the reflowed samples was cross sectioned and polished with $1 \mu \mathrm{m}$ and $0.3 \mu \mathrm{m} \mathrm{Al}_{2} \mathrm{O}_{3}$ powders. The microstructure of the joints was studied by scanning electron microscopy (SEM-EDX; JEOL JSM 6610 and JEOL 7600F). The average thickness of the IMC layer at the interface $\mathrm{Cu} / \mathrm{sub}$ strate was calculated using the Digimizer software according to the following equation:

$$
x=S / L
$$

where $x$ is the average thickness of the IMC layer, $L$ is the length, and $S$ is the integral contour area of the intermetallic layer at the interface.

The shear strength of the joints was measured by a push-off method (Zwick/Roell Z 100) employing a loading rate of $1 \times 10^{-3} \mathrm{~m} \mathrm{~min}^{-1}$.

\section{RESULTS AND DISCUSSION}

Figures 2 and 3 show the microstructural evolutions of the SAC solder/Cu interface without ceramic nanoadditions and with 0.5 wt.\% and 
Table I. Characteristics of used ceramic nanopowders ${ }^{19}$

\begin{tabular}{|c|c|c|c|}
\hline Material & Particle average size (nm) & Specific surface area $\left(10^{3} \mathrm{~m}^{2} \mathrm{~kg}^{-1}\right)$ & True density $\left(\mathrm{kg} \mathrm{m}^{-3}\right)^{20}$ \\
\hline Nano-SiO ${ }_{2}$ & $10-15$ & $180-270$ & 2.65 \\
\hline Nano- $\mathrm{TiO}_{2}$ & $10-15$ & $100-150$ & 4.17 \\
\hline Nano- $\mathrm{ZrO}_{2}$ & $10-15$ & $70-110$ & 5.68 \\
\hline
\end{tabular}

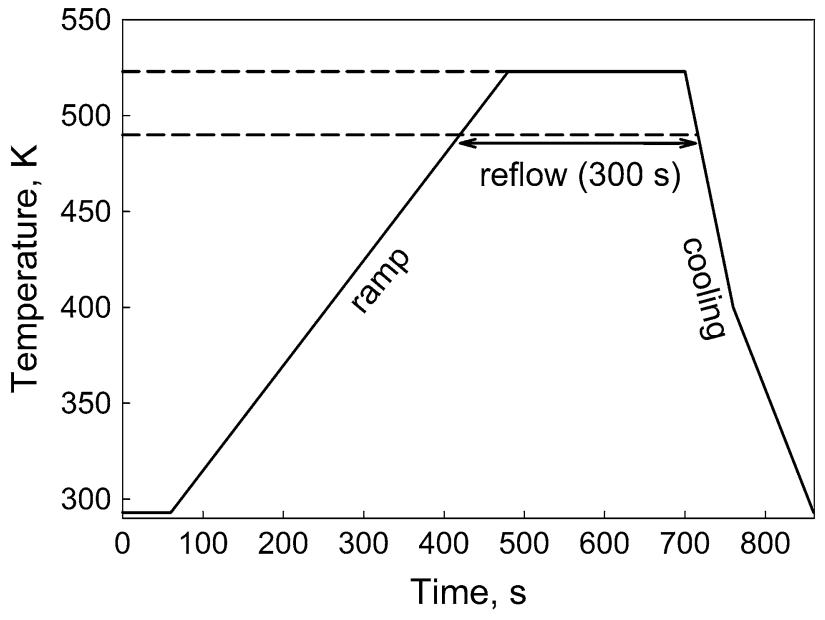

Fig. 1. Reflow temperature profile of solder/Cu joint.

1.0 wt.\% of $\mathrm{SiO}_{2}, \mathrm{TiO}_{2}$ and $\mathrm{ZrO}_{2}$ nanopowders, respectively. As seen in Fig. 2a, a discontinuous scallop-type IMC layer formed cusps at the solder/substrate interface extending into the solder matrix. Furthermore, in some regions cracks were observed along the line, which conditionally separates the IMC zone from the solder bulk; in addition, the so-called Kirkendall voids were formed in the $\mathrm{Cu}-\mathrm{Cu}_{3} \mathrm{Sn}$ and $\mathrm{Cu}_{3} \mathrm{Sn}-\mathrm{Cu}_{6} \mathrm{Sn}_{5}$ interfaces. A linescan analysis of the SAC305/Cu joint demonstrated the presence of a thin $\mathrm{Cu}_{3} \mathrm{Sn}$ layer of about $0.3 \mu \mathrm{m}$ at the interface zone, while the average thickness of the entire $\mathrm{Cu}_{6} \mathrm{Sn}_{5} / \mathrm{Cu}_{3} \mathrm{Sn}$ layer at the interface was about $4.3 \mu \mathrm{m}$ (Fig. 2b). This is consistent with the results of other investigators. ${ }^{21} \mathrm{~A}$ comparatively large amount of IMC phases $(l \approx 5-30 \mu \mathrm{m}, d \approx 2-$ $20 \mu \mathrm{m})$ was also observed in the bulk solder with eutectic structure. It was previously established that primary formed $\mathrm{Ag}_{3} \mathrm{Sn}$ grains in the $\mathrm{SAC}$ solder/Cu are very small compared to the $\mathrm{Cu}_{6} \mathrm{Sn}_{5}$ grains and are partly adsorbed on the $\mathrm{Cu}_{6} \mathrm{Sn}_{5}$ surface. $^{22}$

The discontinuous scallop-type IMC in the SAC305 solder joints were transformed to a more continuous scallop-type IMC with $0.5 \mathrm{wt} . \%$ of nanoadditions (Fig. 3a-c). Furthermore, cusps became rounded, and deep channels between them were observed in case of all ceramic nanopowders. At the same time, we did not notice formation of the $\mathrm{Cu}_{3} \mathrm{Sn}$ IMC layer at the interface for all investigated SAC305-nanoceramic joints (Fig. 4, for solder joints with 0.5 wt.\% ceramic nanoparticles). These effects were accompanied by a decrease of the average thickness of the IMC layer at the interface (Fig. 5). Similar behavior was reported in many previous studies ${ }^{8,11,12,23}$ and explained based on the theory of adsorption of a surface-active material. This means that the addition of ceramic nanoparticles increases the content of surface-active material in the solder joint and maximizes the amount of adsorbed particles on the IMC surface. However, an increase of the amount of adsorbed material decreases the IMCs' surface energy accompanied by a decrease of their growth rate, both in the bulk and at the interface. As shown in Fig. 3a-c, no large IMC grains appeared in the solder matrix in the SAC-composite solder joints.

A further increase of the ceramic nanoparticles' amount up to $1 \mathrm{wt}$ \% did not lead to any significant changes in the shape or size of the IMC layer at the interface and showed a microstructure in the bulk similarly refined as with the initial addition of 0.5 wt.\% (Fig. 3d-f). The insignificant increase of the IMC average thickness at the interface with $1 \mathrm{wt} . \%$ of ceramic nanoadditions compared to 0.5 wt. $\%$ at additions of nanopowders $\mathrm{SiO}_{2}$ and $\mathrm{ZrO}_{2}$ could be caused by agglomeration and segregation, which leads to the decrease in the surface energy of those and reduces the amount of surfaceactive nanoparticles. In contrast, a continuous decrease was revealed in the average thickness of the IMC layer by increasing the amount of $\mathrm{TiO}_{2}$ nanoinclusions up to $1 \mathrm{wt} . \%$. In the literature, an increase of the IMCs' average thickness at the nanocomposite $\mathrm{SAC}$ solder/Cu interface with an increase of the $\mathrm{SiO}_{2}$ nanoparticle content up to 1.0 wt. $\%$ was also detected in Ref. 11. A similar trend was reported in Ref. 12 for SAC solder joints with up to 1.25 wt.\% of $\mathrm{TiO}_{2}$ nanoadditions using $\mathrm{Cu}$ pads plated with $0.2 \mu \mathrm{m} \mathrm{Sn}$. An insignificant decrease of the average thickness of the IMC layer at the interface solder/OSP-Cu was reported by adding 1 wt.\% nano $\mathrm{ZrO}_{2}$ into SAC305 solder powder. ${ }^{23}$ In surprising contrast, the same authors showed a continuous decrease of the average thickness of the IMC at the interface up to $3.0 \mathrm{wt} . \%$ of nano $\mathrm{ZrO}_{2}$ using $\mathrm{Au} / \mathrm{Ni}$ metallized $\mathrm{Cu}$ pads. ${ }^{13}$ Our experimental results showed that the average total thickness of the IMC layer formed at the $\mathrm{Cu} /$ solder/ $\mathrm{Cu}$ interfaces using the SAC305 solder paste is higher compared with the literature data (Fig. 5). This fact might be due to formation of a $\mathrm{Cu}_{6} \mathrm{Sn}_{5} /$ 

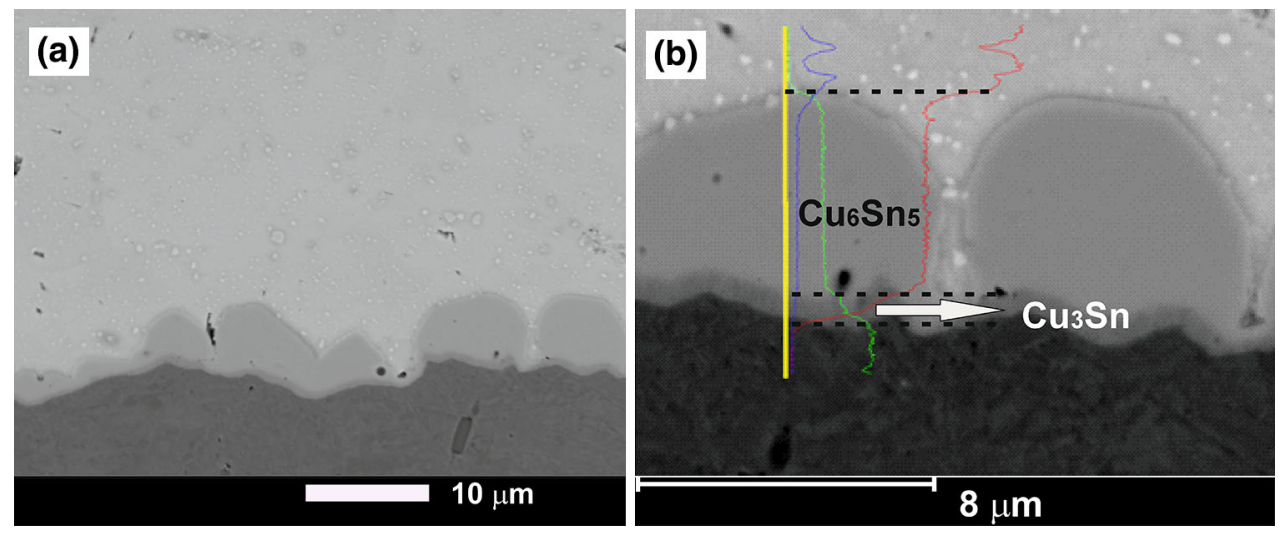

Fig. 2. SEM micrograph of an as-solidified solder joint made from SAC305 solder paste (a) and the corresponding concentration profiles for Ag, $\mathrm{Cu}$, and $\mathrm{Sn}$ across the solder joint (Interface + Matrix) by EDX line scanning (b).
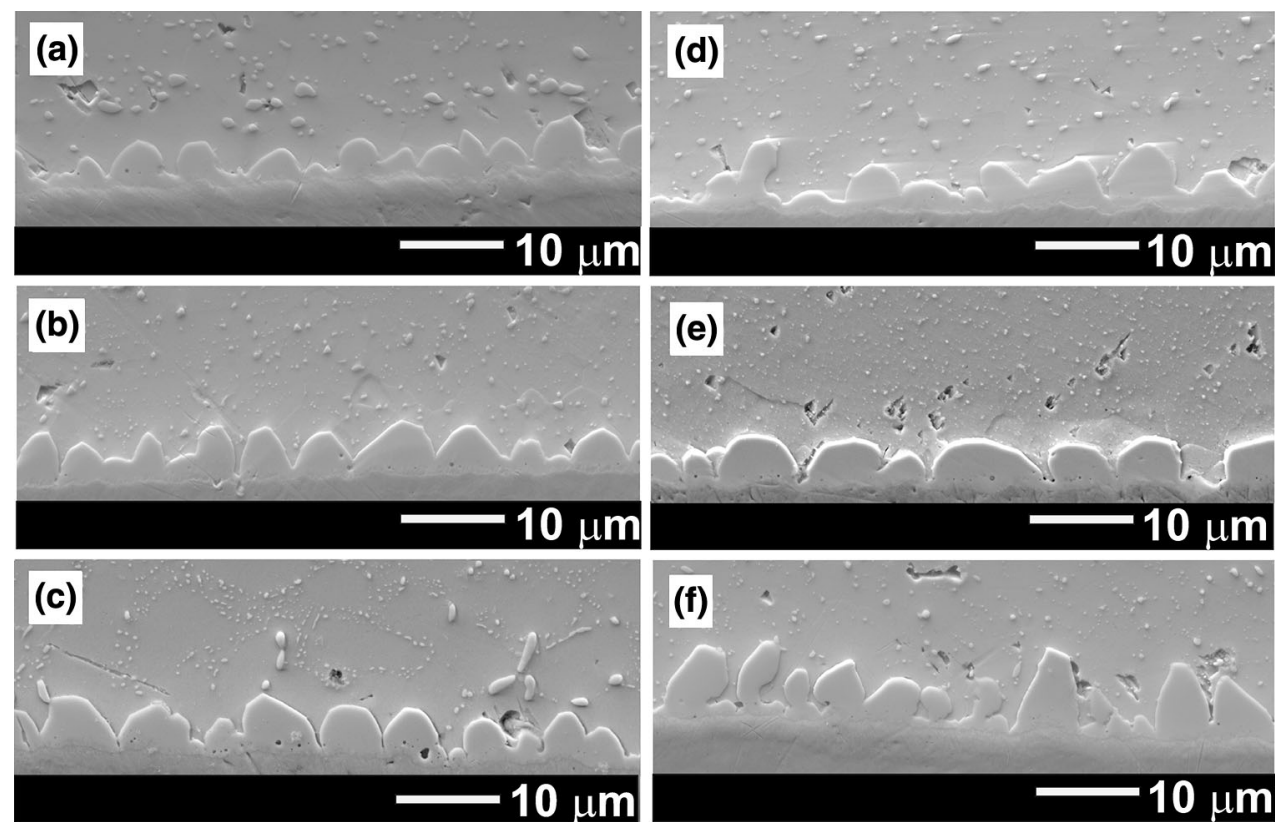

Fig. 3. SEM micrographs of as-solidified SAC305-nanoceramic ((a, d) nano $\mathrm{SiO}_{2},(b, e)$ nano $\mathrm{TiO}_{2}$, and (c, f) nano $\left.\mathrm{ZrO} 2\right)$ solder joints depending on the concentration: $0.5 \mathrm{wt} \%(\mathrm{a}-\mathrm{c})$, and $1.0 \mathrm{wt} . \%(\mathrm{~d}-\mathrm{f})$.

$\mathrm{CuSn}_{3}$ layer, while in Refs. 11 and 23 only the $\mathrm{Cu}_{6} \mathrm{Sn}_{5}$ layer was found after reflow. Comparing the reflow conditions of above the mentioned studies with those in the present paper: in all studies SAC305/Cu solder joints were heated up to $523 \mathrm{~K}$ (maximum temperature) but with different reflow times, namely, $50 \mathrm{~s}$ in Ref. 11 but $300 \mathrm{~s}$ in Ref. 23 and in the present study. It should be noted that in these papers no information on the size of the solder joints is given, which could also have an effect on the solder joint characteristics. At the same time, experimental results of the average total thickness of the IMC layer using SAC305 solder paste with ceramic nanoadditions are in satisfactory agreement with literature data (Fig. 4). It should also be noted, that the difference in the average total thickness of the IMC layer at the upper interface
$\mathrm{Cu} /$ solder compared to the lower interface solder/Cu was below $0.15 \mu \mathrm{m}$. This value is within the error limit and indicates that there was no significant difference in the amount of ceramic nanoparticles at upper and lower interfaces.

The changes in the microstructure of nanocomposite solder joints described above should also result in changes of the mechanical properties. Therefore, it was decided to investigate the shear strength, as one of the main properties to the joint reliability.

As seen in Fig. $6 \mathrm{a}$, the addition of 0.5 wt.\% ceramic nanoparticles can remarkably increase the shear strength of the SAC305 solder joints, especially in the case of nano- $\mathrm{SiO}_{2}$ particles. Furthermore, the increase in shear strength was less significant for $1.0 \mathrm{wt}$.\% of ceramic nanoinclusions, 
(a)
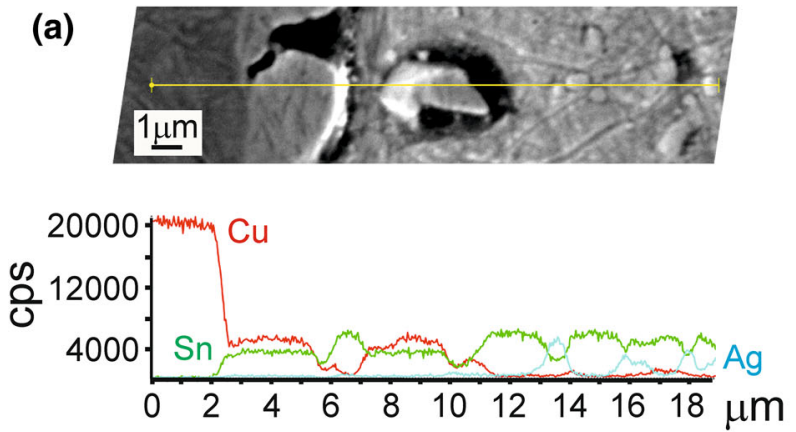

(b)
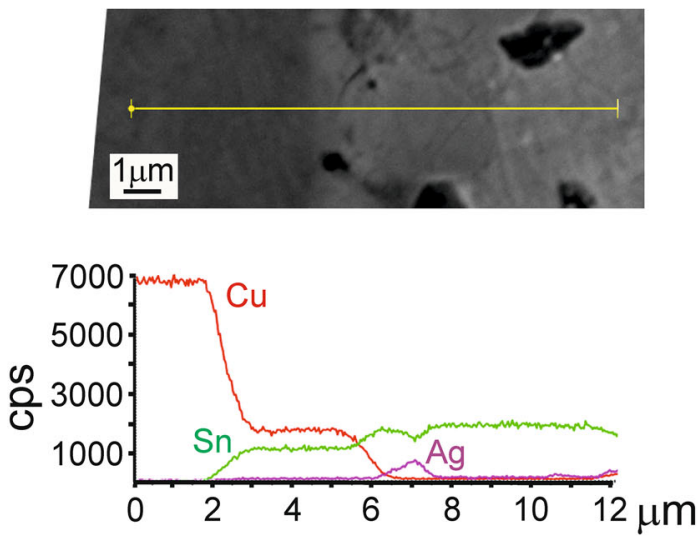

(c)
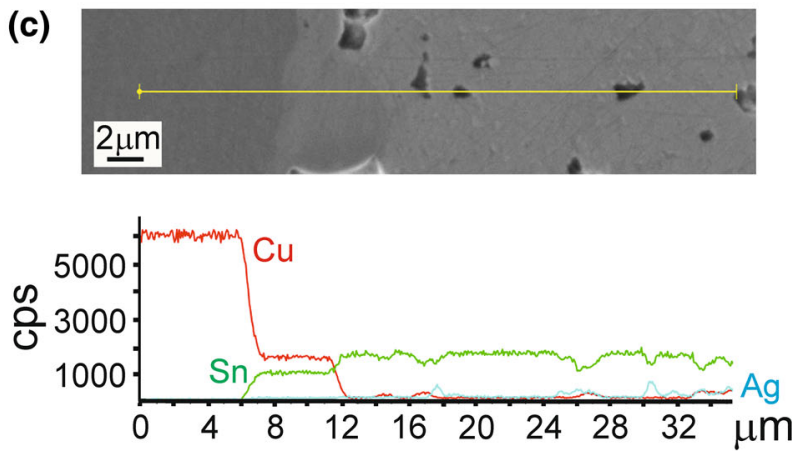

Fig. 4. SEM micrographs with concentration profiles for $\mathrm{Ag}, \mathrm{Cu}$ and $\mathrm{Sn}$ across the solder joint (Interface + Matrix) by EDX line scanning of as-solidified solder joints made from SAC 305 solder paste reinforced with nano $\mathrm{SiO}_{2}(\mathrm{a})$, nano $\mathrm{TiO}_{2}$ (b) and nano $\mathrm{ZrO}_{2}$ (c).

except for nano- $\mathrm{ZrO}_{2}$. The presented results show that both the average total thickness of the IMC layer at the interface and the shear strength depend on the quantities of ceramic nanoparticles. Taking into account that the ceramic nanoparticles are "unreacted" with the solder matrix and have the same average size, the difference in the shear strength should be connected with the agglomeration process and/or the characteristics of the mobility rate of the nanoparticles.

The observed value of the shear strength for unreinforced SAC305/Cu joints is lower than the value reported in Refs. 11 and 13 (Fig. $6 \mathrm{~b}$ and c). This fact could be caused by formation of the thicker IMC layers as compared with those reported in

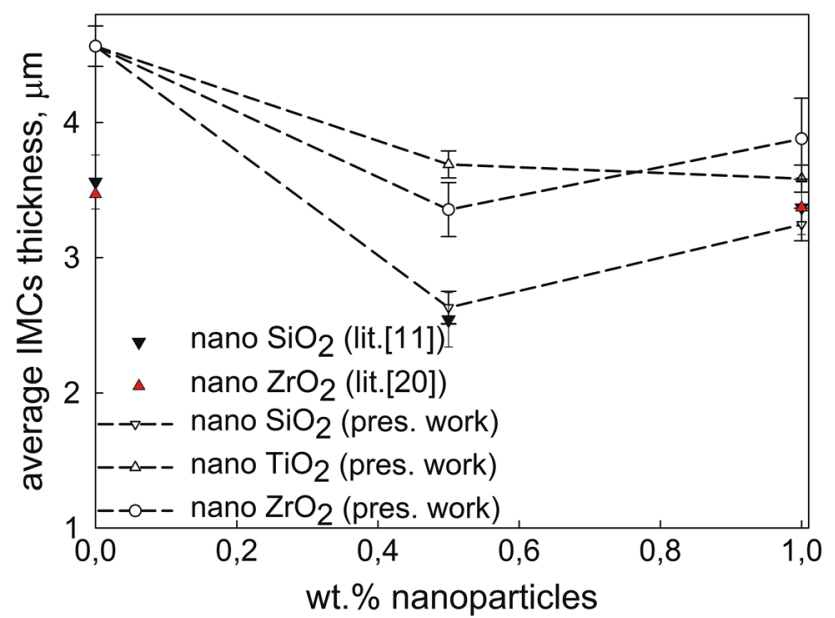

Fig. 5. Average total thickness of Cu-Sn IMCs layers with respect to the increasing of ceramic nanoadditions.

these papers. In addition, these authors did not observe the presence of the brittle $\mathrm{Cu}_{3} \mathrm{Sn}$ phase at the interface, which deteriorates the mechanical properties of the joints. The changes of the shear strength of the joints with nano- $\mathrm{SiO}_{2}$ and nano- $\mathrm{TiO}_{2}$ additions are more pronounced than reported in Ref. 11; however, the tendency is the same: the shear properties were enhanced by minor ceramic additions to a maximum near 0.5 wt.\% and further decreased by about $13 \%$ with 1 wt. $\%$ of nano- $\mathrm{SiO}_{2}$ (Fig. 6b). There is also a satisfactory agreement between experimental and literature data of the shear strength for SAC305 solder joints reinforced with 0.5 wt. $\%$ and 1.0 wt.\% of nano- $\mathrm{ZrO}_{2}$ (Fig. 6c). To the best of our knowledge, no literature data of the shear strength for $\left(\mathrm{SAC}_{0} 05-\right.$ nanoTiO $\left._{2}\right) / \mathrm{Cu}$ solder joints are available.

Noticeably, the sample with 1 wt. $\% \mathrm{SiO}_{2}$ showed more featured regions in the bulk solder joints as compared with those with $0.5 \mathrm{wt} . \%$, while microsized $\mathrm{Cu}_{6} \mathrm{Sn}_{5}$ particles $(d=1-2 \mu \mathrm{m}, l=3-4 \mu \mathrm{m})$ had completely disappeared. It is suggested that these regions correspond to brittle nanosized $\mathrm{Cu}_{6} \mathrm{Sn}_{5}$ and $\mathrm{Ag}_{3} \mathrm{Sn}$ IMC grains with adsorbed ceramic nanoparticles acting as preferential sites for crack initiation during push-off test. Literature investigations of the tensile strength for the SAC305 solder joint reinforced with nano $\mathrm{CeO}_{2}$ indicated a gradual increase in this mechanical property for joints with up to 0.5 wt.\% ceramic nanoparticles and a decrease with a further increase in nano- $\mathrm{CeO}_{2}$ content. This behavior was explained by formation of the brittle cluster-like regions with a high concentration of ceramic nanoparticles inside the joint. ${ }^{24}$ It was also mentioned in Refs. 17 and 25 that an increased amount of ceramic nanoparticles leads to a higher degree of microporosity, which could form fine microscopic cracks, culminating in the failure of nanocomposite SAC solder joints. 

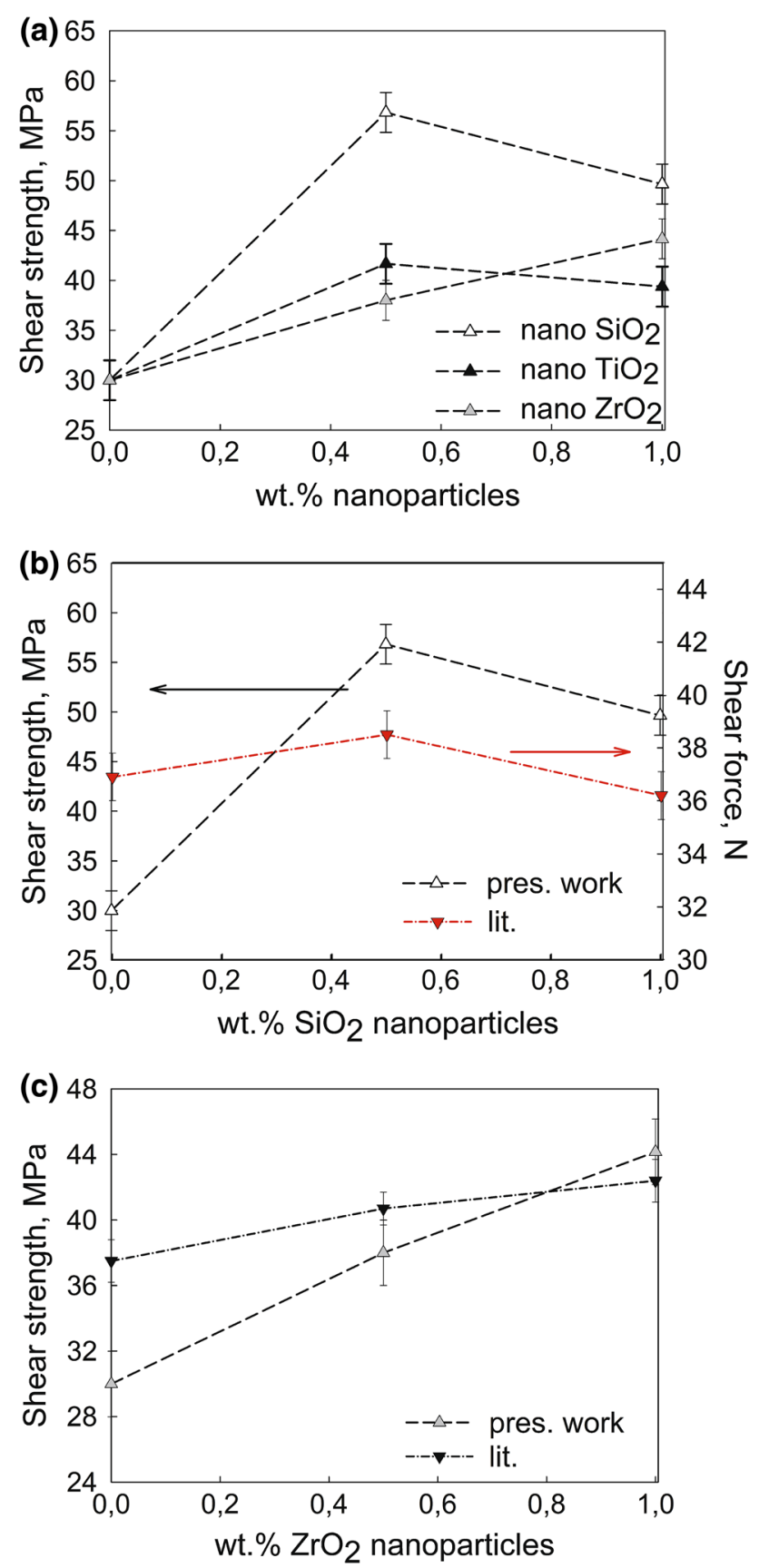

Fig. 6. Shear strength of SAS305-nanoceramic solder joints: (a) experimental values and comparison with literature data (b) nano $\mathrm{SiO}_{2} ;{ }^{11}$ (c) nano $\mathrm{ZrO}_{2} \cdot{ }^{13}$

In contrast, $\mathrm{TiO}_{2}$ particles of a similar size should exhibit less mobility, therefore the adsorption and agglomeration processes proceed more slowly. The differences in effects between $0.5 \mathrm{wt} \%$ and 1.0 wt. $\%$ of nano $\mathrm{TiO}_{2}$ additions were smaller compared to $\mathrm{SiO}_{2}$, while the above mentioned effects of 0.5 wt. $\%$ additions of $\mathrm{TiO}_{2}$ were also less than those of $\mathrm{SiO}_{2}$. It should also be noted that the average size of the "featured regions" in the $(\mathrm{SAC} 305)_{99}\left(\text { nanoTiO }_{2}\right)_{1} / \mathrm{Cu}$ joint was smaller than in the solder joint with 1 wt.\% of nano $\mathrm{SiO}_{2}$. On the other hand, solder joints with $\mathrm{ZrO}_{2}$ nanoinclusions showed a somewhat different behavior: insignificant changes in the average size of the IMC layer at the interface of composite solder joints with $0.5 \mathrm{wt} . \%$ and $1.0 \mathrm{wt} . \%$ combined with an increase in the shear strength for the joint with higher amounts of nano $\mathrm{ZrO}_{2}$.

Based on the presented results, it is suggested that minor amounts of up to $0.5 \mathrm{wt} . \%$ of nano- $\mathrm{SiO}_{2}$ in the SAC solder leads to more profound effects compared to those for $0.5 \mathrm{wt} . \%$ and $1.0 \mathrm{wt} . \% \mathrm{TiO}_{2}$ and $\mathrm{ZrO}_{2}$ nanoinclusions, while further additions of nano- $\mathrm{SiO}_{2}$ lead to a less significant enhancement of the shear strength of the SAC305/Cu joints.

\section{CONCLUSION}

The addition of 0.5 wt.\% ceramic nanoparticles into SAC305 solder leads to more significant changes in the microstructure as well as to a more significant enhancement of the shear strength of the corresponding SAC305/Cu joints compared to higher amounts of ceramic nanoadditions. A comparison of the effects of $\mathrm{SiO}_{2}, \mathrm{TiO}_{2}$, and $\mathrm{ZrO}_{2}$ nanoadditions showed the best shear strength of the joints for the lightest of the used nanopowders, i.e. $\mathrm{SiO}_{2}$. These effects might be caused by different mobility rates of the nanoparticles in the solder paste; for larger amounts of nanoparticles, agglomeration and segregation of ceramic nanoparticles might have occurred during reflow accompanied by a migration with the flux from the bulk onto the interface solder/substrate.

\section{ACKNOWLEDGEMENTS}

Open access funding provided by University of Vienna. Financial support for this study came from the Austrian Science Fund (FWF) under Project Nos. P 26304 and P 27049, and Slovak Scientific Grant Agency under Project Nos. VEGA 2/0172/16 and VEGA 2/0189/14.

\section{OPEN ACCESS}

This article is distributed under the terms of the Creative Commons Attribution 4.0 International License (http://creativecommons.org/licenses/by/4.0/), which permits unrestricted use, distribution, and reproduction in any medium, provided you give appropriate credit to the original author(s) and the source, provide a link to the Creative Commons license, and indicate if changes were made.

\section{REFERENCES}

1. X.C. Zhao, Y.N. Wen, Y. Li, Y. Liu, and Y. Wang, J. Alloys Compd. 662, 272 (2016).

2. G. Chen, F.S. Wu, C.Q. Liu, V.V. Silberschmidt, and Y.C. Chan, J. Alloys Compd. 656, 500 (2016).

3. L. Zhang, J.G. Han, Y.H. Guo, and L. Sun, J. Mater. Sci. Mater. Electron. 26, 3615 (2015).

4. M. Sobhy, A.M. El-Refai, M.M. Mousa, and G. Saad, Mat. Sci. Eng. A 646, 82 (2015).

5. L. Sun and L. Zhang, Adv. Mater. Sci. Eng. 2015, 639028 (2015). 
6. L. Zhang and K.N. Tu, Mat. Sci. Eng. R 82, 1 (2014).

7. H.R. Kotadia, P.D. Howes, and S.H. Mannan, Microelectron. Reliab. 54, 1253 (2014).

8. A.T. Tan, A.W. Tan, and F. Yusof, Sci. Technol. Adv. Mat. 16, 033505 (2015).

9. L.C. Tsao, R.W. Wu, T.H. Cheng, K.H. Fan, and R.S. Chen, Mater. Des. 50, 774 (2013).

10. Y. Tang, G.Y. Li, and Y.C. Pan, Mater. Des. 55, 574 (2014).

11. Y. Wang, X.C. Zhao, X.C. Xie, Y. Gu, and Y. Liu, J. Mater. Sci. Mater. Electron. 26, 9387 (2015).

12. J.C. Leong, L.C. Tsao, C.J. Fang, and C.P. Chu, J. Mater. Sci. Mater. Electron. 22, 1443 (2011).

13. A.K. Gain, Y.C. Chan, and W.K.C. Yung, Microelectron. Reliab. 51, 2306 (2011).

14. S. Chellvarajoo, M.Z. Abdullah, and Z. Samsudin, Mater. Des. 67, 197 (2015).

15. S.L. Tay, A.S.M.A. Haseeb, M.R. Johan, P.R. Munroe, and M.Z. Quadir, Intermetallics 33, 8 (2013).
16. A.S.M.A. Haseeb and T.S. Leng, Intermetallics 19, 707 (2011).

17. T.H. Chuang, M.W. Wu, S.Y. Chang, S.F. Ping, and L.C. Tsao, J. Mater. Sci. Mater. Electron. 22, 1021 (2011).

18. C. Schmetterer, H. Ipser, and J. Pearce, ELFNET COST Action 531-Handbook of Properties of SAC Solders and Joints (Vydavatelstvi Knihar: Brno, 2008), p. 210.

19. Catalog, Powder Nanoparticles (TECNAN Navarrean Nanoproducts Technology, Los Arcos, 2012), p. 2.

20. W.M. Haynes, CRC Handbook of Chemistry and Physics, 96th ed. (Boca Raton: CRC Press, 2015), p. 2677.

21. C.W. Hwang, J.G. Lee, K. Suganuma, and H. Mori, J. Electron. Mater. 32, 52 (2003).

22. L.C. Tsao, J. Alloys Compd. 509, 2326 (2011).

23. G.A.K. Gain, T. Fouzder, Y.C. Chan, and W.K.C. Yung, J. Alloys Compd. 509, 3319 (2011).

24. A. Roshanghias, A.H. Kokabi, Y. Miyashita, Y. Mutoh, and H.R. Hosseini, J. Mater. Sci. Mater. Electron. 24, 839 (2013).

25. L.C. Tsao, Mater. Sci. Eng. A 529, 41 (2011). 